\title{
NITRATE ACCUMULATION, NITROGEN BALANCE AND CATION-ANION RATIO DURING THE REGROWTH OF PERENNIAL RYEGRASS ${ }^{1}$ )
}

\author{
W. DIJKSHOORN \\ Institute for Biological and Chemical Research on Field Crops and Herbage, \\ Wageningen, Netherlands
}

\begin{abstract}
SUMMARY
The regrowth of perennial ryegrass was harvested on various dates in a pot culture experiment for the purpose of studying the nitrogen, protein and nitrate content and the cation-anion ratio in the yield at different stages of regrowth.

Nitrate accumulation occurred until a specific yield level was reached which was critical with respect to the nitrogen supply. Below this critical yield the nitrogen percentage in the yield gradually declined as a result of the decreasing capacity of the dry matter produced to assimilate nitrogen. After the critical yield was exceeded nitrate disappeared from the leaves and no further nitrogen was taken up during the subsequent growth, so that the nitrogen percentage in the yield decreased more rapidly.

At first there was a gradual increase in the cation-anion ratio as the grass aged. After the critical yield for nitrogen depletion was exceeded there was a higher rate of increase.

The relationship between cation-anion ratio and nitrogen status is connected with nitrogen metabolism.
\end{abstract}

\section{INTRODUCTION}

In the previous reports (Dijkshoorn, 1957) use was made of BEAR's rule relating to the constant cation-anion ratio (BEAR, 1950) in order to interpret the effects of fertilization on the mineral composition. Although the effects found were in qualitative agreement with this rule, it was found that increasing nitrogen content in the yield caused by nitrogenous fertilization may lead to a decrease in the cation-anion ratio (Dijkshoons, 1958). The same deviation from BEAR's rule was observed by Scharrer and Jung (1955) in ryegrass and is connected by these authors with nitrogen metabolism.

It is known that there is a decrease in the nitrogen percentage of the yield during the regrowth of grass (VAN Itallie, 1934, Frankena, 1934). It may be expected that the cation-anion ratio will be relatively lower in nitrogen-rich young grass, and that the decrease in the nitrogen percentage which occurs as the yield ages will be accompanied by an increase in the cation-anion ratio.

Since nitrogen has a substantial share in the nutrient uptake, in the experiment discussed here the uptake of this element during regrowth was first investigated in greater detail. As an index to the availability, use was made of the internal nitrate level in the leaves, and as an index to the utilization of nitrogen of the protein nitrogen content in the yield. In this way an attempt was made to distinguish between the decrease in the nitrogen percentage caused by internal factors, and the decrease resulting from the depletion of the external amount of nitrogen available in the soil. After a general picture had been obtained of the changes in the nitrogen status of the plants during regrowth, it was ascertained in what manner the cation-anion ratio changes.

1) Received for publication January 11, 1958. 
In conclusion, an attempt was made on the basis of certain assumptions relating to the nitrogen metabolism to find an explanation of the high anion uptake compared to the cation uptake.

\section{EXPERIMENTAL}

Use was made of a river clay soil having $52 \%$ clay fraction $(<16 \mu), 8 \%$ organic matter and a $\mathrm{pH}\left(\mathrm{H}_{2} \mathrm{O}\right)$ of 7 . For each pot a quantity of moist soil, corresponding to $5 \mathrm{~kg}$ of dry soil, was mixed with the required amount of water to which was added $20 \mathrm{ml} 1 \mathrm{M}$ potassium monophosphate and a measured amount of $0.5 \mathrm{M}$ ammonium nitrate. Thus all pots received the same basic dressing of potassium and phosphate. One series of pots was given no ammonium nitrate and three other series 140,560 and $700 \mathrm{mg} \mathrm{N}$ per pot respectively. The prepared pots were planted with shoots of perennial ryegrass and kept in the shade for three days. The herbage was then clipped to a height of $3 \mathrm{~cm}$ above the soil and placed in the greenhouse. Evaporation losses were made up daily with demineralised water.

Eight days after the commencement of regrowth the first pots of each series were harvested by clipping the herbage to the original height. The remaining pots were successively harvested at three or four-day intervals. The harvesting was always carried out at 2 p.m. The herbage was dried immediately in an air-stream of $110^{\circ} \mathrm{C}$ and subsequently dried at $105^{\circ} \mathrm{C}$ until the weight was constant.

The experiment was performed in July. A late-flowering pasture type of perennial ryegrass was employed. The plants flowered at the end of the observation period.

The herbage originating from the series with nil and $700 \mathrm{mg} \mathrm{N}$ per pot was examined for total Kjeldahl nitrogen and protein nitrogen. The latter represents nitrogen precipitated, after heating with trichloroacetic acid, at room temperature overnight. The herbage of the series containing 140 and $560 \mathrm{mg} \mathrm{N}$ per pot in the dressing was examined for total nitrogen, potassium, sodium, magnesium, calcium, chlorine, phosphorus and sulphur ${ }^{2}$ ).

During the experiment the herbage of all series was regularly sampled in order to determine the nitrate content of the leaves. Small samples (3 $\mathrm{g}$ of fresh herbage) were finely cut for this purpose and rubbed finely together after addition of copper sulphate, calcium oxide, coarse quartz sand and water. After the filtrate had been filtered off and diluted, its nitrate content was determined by a modified xylenol method, the nitroxylenol formed in the acid nitration medium being extracted with isopropyl ether and the resultant ethereal solution extracted with a dilute sodium hydroxide solution. The extinction of the resultant sodium nitroxylenate solution was measured at $440 \mathrm{~m} \mu$. Before addition of xylenol, any nitrite eventually present was converted into nitrate by adding a few drops of permanganate solution and excess permanganate removed by adding a little solid oxalic acid.

2) The writer is indebted to the staff of the analytical department who carried out the analyses. 


\section{Discussion}

A better idea of the changes occurring during the regrowth in the nitrogen percentage of the yield is obtained by first representing the results in terms of the total quantity of nitrogen present in the yield and the quantity of dry matter produced.

In Figure 1 the quantities of total nitrogen, protein nitrogen and nitrate nitrogen are plotted against the dry matter yield. The ordinate values are calculated from the yield and its nitrogen percentage content. Graph A relates to the series without nitrogen dressing and graph B to the series with $700 \mathrm{mg}$ $\mathrm{N}$ in the dressing.

In the unfertilised series $A$ the amount of nitrate accumulated by the yield increases until a yield of $17 \mathrm{~g}$ of dry matter is reached. In the fertilized series $\mathrm{B}$ the nitrate accumulation goes beyond this stage and does not end until a yield of $27 \mathrm{~g}$ of dry matter has been reached. After these yields, which are apparently critical for nitrate accumulation, have been exceeded the amount of nitrate decreases again.

$\mathrm{mg} \mathrm{N}$

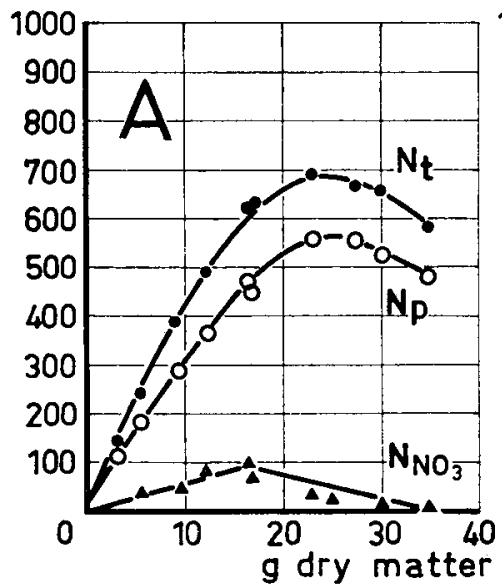

$\mathrm{mg} N$

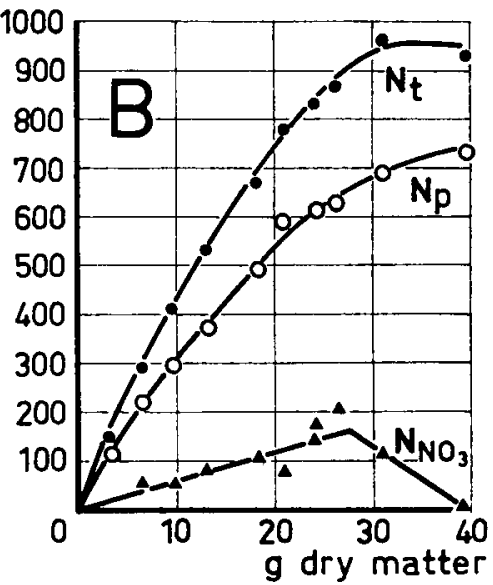

Fig. 1 Amounts in mg of total nitrogen $\left(\mathrm{N}_{\mathrm{t}}\right)$, protein nttrogen $\left(\mathrm{N}_{\mathrm{p}}\right)$ and nitrate NITROGEN $\left(\mathrm{NNO}_{3}\right)$ PRESENT IN THE YIELD PLOTTED AGAINST THE AMOUNT OF DRY MATTER PRODUGED.

A : without nitrogen fertilizer.

B : fertilized with $700 \mathrm{mg} \mathrm{N}$ per pot as ammonium nitrate.

In the range of the nitrate accumulation the relationship between nitrate and yield is shown by a straight line drawn through the origin which has the same slope in the A and B series. Thus so long as the critical yield is not exceeded the amount of nitrate increases in proportion to the yield, and about the same amount of nitrate is accumulated in both series per gram of dry matter produced. The only effect of fertilization is that the nitrate accumulation in the fertilized series is maintained up to a higher yield level.

The total amount of nitrogen taken up by the yield and the amount converted into protein is best shown in the graphs by means of lines curving slightly towards the abscis even in the range of nitrate accumulation. In the range below the critical yield of the unfertilized series $\mathrm{A}$, viz. below $17 \mathrm{~g}$, these lines are identical in both series. After the critical yield in each of the 
series has been passed, there is practically no further increase in the amounts of total nitrogen and protein nitrogen.

Thus in the range of the lower yields in which nitrate is accumulated, the amount of nitrogen taken up and converted into protein by the fertilized plants per gram of dry matter produced is no more than that taken up and converted into proteinaceous substance by the unfertilized plants. This is only so after the 17 gram yield, which is critical for the unfertilized plants, has been exceeded. As early as the first regrowth these amounts do not increase in proportion to the yield but relatively lag behind the growth. As soon as the critical yield has been reached, this being indicated by the subsequent disappearance of nitrate, the uptake of nitrogen and its conversion into protein practically comes to a halt as growth proceeds further.

The changes in the nitrogen percentage of the yield are summarized in Figure 2. In order to show these changes in a proportionate manner for the different fractions use is made of a logarithmic ordinate.

The leaves first show a high nitrate percentage which in the case of the unfertilized plants suddenly begins to decrease after twenty days. This decrease during the further course of growth is shown by a straight line which indicates that after the critical yield has been exceeded the nitrate percentage decreases at a rate corresponding to a half-value time of four days. The decrease in the nitrate percentage of the fertilized plants proceeds in the same way, but is deferred to a later stage of regrowth and does not commence till the thirtieth day.

Hence the fertilized plants have a longer period of nitrate accumulation, since the deficit appears at a higher yield level. During the period of nitrate accumulation the uptake can easily keep pace with the consumption in the yield because a high internal level of unassimilated nitrate is maintained.

Figure 1 already showed that in this stage of regrowth the fertilized plants do not take up more nitrogen per gram of dry matter than the unfertilized plants. During this part of the regrowth period, an increase in the concentration of nitrate available in the soil has no effect on the uptake because at this rate of growth the fertilized plants are unable to assimilate more nitrogen than is already assimilated by the unfertilized plants.

During the period of nitrate accumulation the trend of total nitrogen and protein nitrogen percentage in Figure 2, can accordingly be shown by lines occupying the same place and having the same slope in the A and B series. In this case the nitrogen percentage in the yield and the rate at which it decreases is not affected by an extra supply of nitrogen in the dressing.

During growth the nitrogen uptake is apparently not affected by the gradual depletion of available nitrogen until this depletion has reached a certain critical level. Supplying additional nitrogen to the dressing does not alter the rate of decrease of the nitrogen percentage of the yield, the only result being that the decrease is able to proceed at the same rate over a longer period.

Since it can be observed that the external nitrogen supply suddenly becomes insufficient for the maintenance of a high internal nitrogen level, two stages may be clearly distinguished in the trend of the nitrogen percentage of the yield. In the first stage preceding the disappearance of accumulated nitrate, the nitrogen percentage decreases at a definite rate, this being related 
Fig. 2 Percentage content of total niTROGEN ( $\left.\mathrm{N}_{\mathrm{t}}\right)$; PROTELN NITROGEN $\left(\mathrm{N}_{\mathrm{p}}\right)$ AND NITRATE NITROGEN $\left(\mathrm{NNO}_{3}\right.$ IN THE DRY MATTER YIELD, PLOTTED AGAINST THE TIME OF REGROWTH.
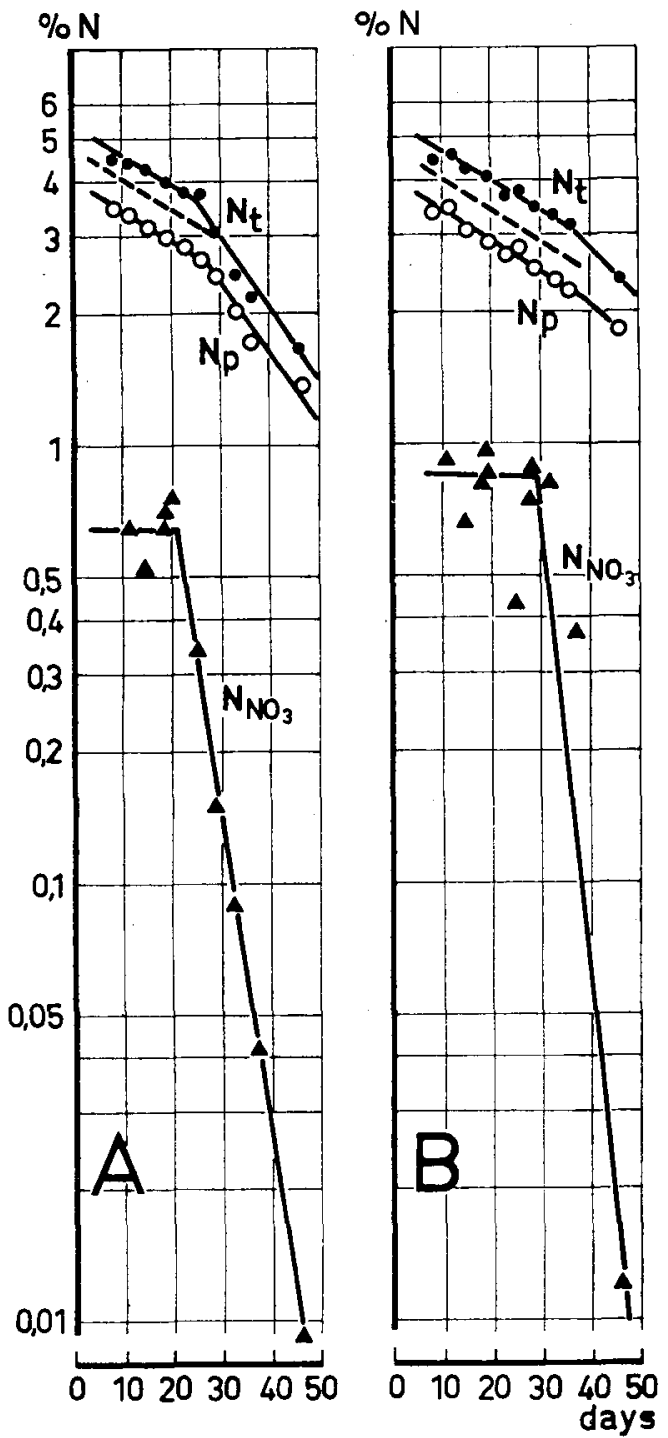

to the above-mentioned non-proportionality between uptake and yield. Since this decrease is independent of the gradual depletion of available nitrogen (because it is not affected by the dressing and is accompanied by a high, constant internal nitrate level) it is clearly determined by an internal factor. This must be connected with a gradual decrease in the capacity of the dry matter produced to assimilate nitrogen, associated with an increasing differentiation. A large part of the carbohydrates produced is stored unchanged in the stems (Aluberd, 1957) so that these parts of the plant are found to have a lower nitrogen percentage.

A relative increase in the part of the carbohydrates not directly involved in nitrogen metabolism but used as a reserve or for the formation of supporting tissue, will be reflected in a decrease in the amount of nitrogen 
assimilated per gram of dry matter produced. In this stage the high internal level of unassimilated nitrate is probably the immediate cause of the nitrogen uptake not being increased by a dressing.

In the second stage, after the critical yield has been exceeded, the nitrogen percentage decreases more rapidly. Since the plants still have a high internal nitrogen level, growth can continue, but the degree of depletion of available nitrogen precludes any further uptake thereof. Hence in this case the rate at which the nitrogen percentage decreases is determined by a dilution, caused by growth, of the nitrogen taken up in the preceding period.

Owing to the late appearance of the second stage in the fertilized series, the transition cannot be clearly distinguished in this case. In the unfertilized series it is very clearly indicated by the point of deflection of the lines for total nitrogen and protein nitrogen. In the second stage these lines are in closer proximity to each other, this being related to the disappearance of the nitrate fraction from total nitrogen. The pecked lines represent total nitrogen minus nitrate nitrogen, and it is easy to see from them that their linear distance from protein nitrogen is practically everywhere the same, little change being effected in the ratio (logarithmic ordinate) of protein to total nitrogen minus nitrate by the time of regrowth or dressing.

In the second stage in series A the slope of the lines for total and protein nitrogen indicates the rate of dilution, resulting from growth, of components of which no further amount is taken up. This rate of dilution can be indicated in the logarithmic scale for each component at any desired percentage level by means of a line having the same slope. The nitrate line is much steeper, this being related to the disappearance of nitrate from the yield after the critical yield has been exceeded (cf. Figure 1). The rate at which the nitrate percentage decreases corresponds to a half-value time of four days. By making a graphical correction it is possible to account for the dilution caused by growth, and the half-value time found for the amount of nitrate present in the yield is then approximately six days. Under the conditions of the experiment the residual nitrate from the preceding accumulation period is consumed at this rate by the further growth.

The changes in the ionic concentration of cations and anions in the yield which occurred during regrowth can be demonstrated by means of the data of the other two series. The cations $\mathrm{C}(=\mathrm{K}+\mathrm{Na}+\mathrm{Mg}+\mathrm{Ca})$, the anions $\mathrm{A}(=\mathrm{Cl}+\mathrm{P}+\mathrm{S})$, nitrogen $(\mathrm{N})$ and total anions $(\mathrm{A}+\mathrm{N})$ in $\mathrm{mg}$ equivalents per $\mathrm{kg}$ of dry matter produced are shown graphically in Figure 3. Nitrogen is shown as a monovalent anion, phosphorus is included in the A anions as monovalent (cf. the footnote in the reference Dijkshoorn, 1958). If phosphorus is shown as trivalent, the relationships to be described below remain relatively the same, but the value for total anions is somewhat higher and the cation-anion ratio correspondingly lower. Nitrate is also shown in $\mathrm{mg}$ equivalents per $\mathrm{kg}$ of dry matter. Graph a relates to the series with a low nitrogen dressing (140 mg $\mathrm{N}$ per pot) and graph $\mathrm{b}$ to the series with a higher nitrogen dressing (560 mg N).

The behaviour of series a is substantially the same as that of the unfertilized series. In this case also the fact that the critical yield for the nitrogen supply has been exceeded is reflected in a sudden decrease of nitrate after 

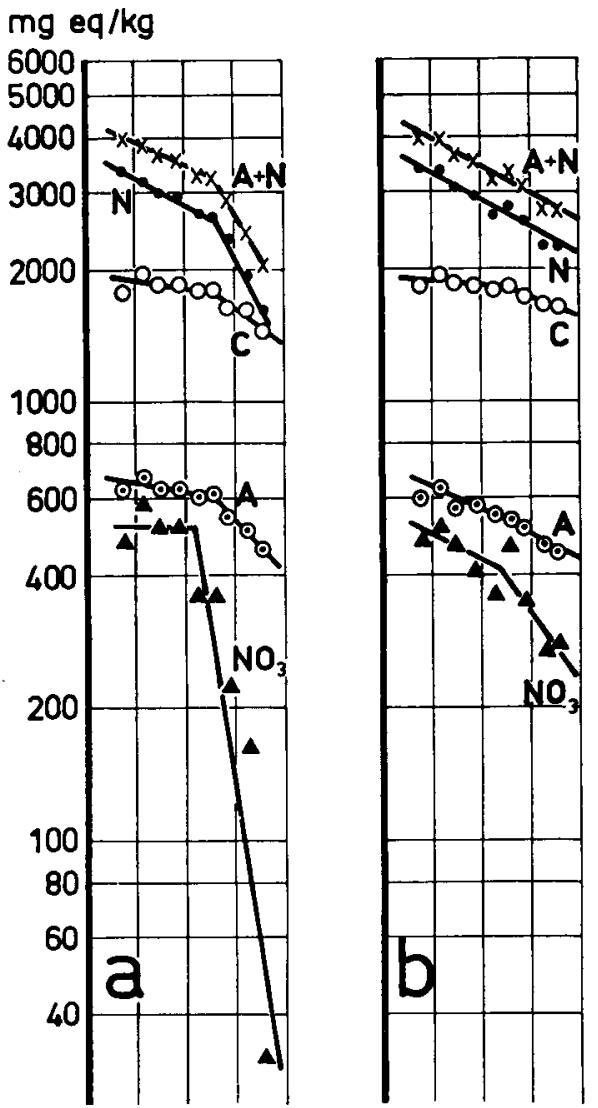

Fig. 3 Ionic concentrations in the yield IN MG EQUIVALENTS PER KG OF DRY MATTER PRODUCED. Nitrogen (N), Cations $\mathrm{C}(=\mathrm{K}+\mathrm{Na}+\mathrm{Mg}+$ Ca) anions $\mathrm{A}(=\mathrm{Cl}+\mathrm{P}+\mathrm{S})$, TOTAL ANIONS $(\mathrm{A}+\mathrm{N})$ AND NITRATE $\left(\mathrm{NO}_{3}\right)$, plotted against the time OF REGROWTH.

The lower graphs show the cationanion ratio: $\mathrm{C} /(\mathrm{A}+\mathrm{N})$.

a: fertilized with $140 \mathrm{mg} \mathrm{N}$ per pot.

$\mathrm{b}$ : fertilized with $560 \mathrm{mg} \mathrm{N}$ per pot.
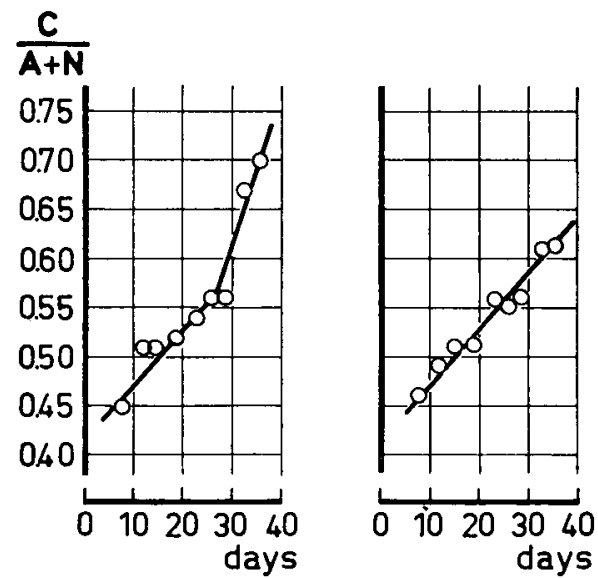

the twentieth day. The increase in the rate of decline of total nitrogen follows some days later ${ }^{3}$ ).

3) Just as in the unfertilized series (Fig. $2 \mathrm{~A}$ ), the discontinuity in total nitrogen follows some days after the discontinuity in nitrate. This is possibly connected with the method of sampling. Nitrate was determined in leaf samples, whereas total nitrogen relates to the total yield consisting of leaves and stems. It is conceivable that nitrate first disappears in the leaves, so that the moment of nitrogen depletion for the total harvest was shown slightly too early by the leaf analysis. The difference in time may also be connected with a conveyance of other nitrogen compounds to the harvest. 
Series $\mathrm{b}$ shows no marked discontinuity in the trend of total nitrogen, nor is there any marked decline in the internal nitrate level in this case. There was, however, such a decline in the series with $700 \mathrm{mg} \mathrm{N}$, but in this instance the observations were continued ten days later so that the disappearance of nitrate could still be observed (compare Figure $2 \mathrm{~B}$ ).

Hence in series a we can again clearly distinguish the first stage in the decline in nitrogen caused by the internal factor, and the second stage of the more rapid decline resulting from nitrogen exhaustion ${ }^{4}$ ). In series $b$ the decline has a practically continuous trend which is entirely determined by the internal factor.

The lines formed by the plots of total cations $\mathrm{C}$ and total anions $\mathrm{A}+\mathrm{N}$ show a convergence which indicates on the logarithmic scale that the cationanion ratio increases as the yield ages. In series a with the low nitrogen dressing this convergence suddenly increases after the critical yield has been passed.

In the lower graphs the cation-anion ratio is plotted on a linear scale. In the first range of series $a$ and during the entire period in series $b$ in which nitrogen in the yield regularly decreases as a result of the internal factor, the ratio increases at a given rate as the yield ages. After the critical yield for nitrogen exhaustion has been passed in series a the rate of increase accelerates.

If the mineral balance employed in this case actually comprises most of the equivalents taken up by the yield (Dijкshoorn, 1958) and the nitrogen uptake is to be wholly regarded as a nitrate uptake, this shows that a large uptake and assimilation of nitrate enables the plant to take up in the yield a much larger equivalent of anions relatively to the cations. A reduction in the intensity of nitrate uptake and assimilation, especially after the exhaustion of the amount available in the soil, causes an increase in the originally low value of the cation-anion ratio.

It has already been assumed that in the reduction of nitrate in the plant hydroxyl would be formed which as a result of exchange might admit to the plant additional nitrate or other anions occurring in the mineral balance, without an equivalent cation uptake being required (Dijkshoorn, 1957).

This assumption might be developed in the following way into a working hypothesis capable of affording a tentative interpretation of what, compared to the cations, is an excessive uptake of nitrate and a greater increase in the cation-anion ratio after nitrogen depletion.

The reduction of nitrate in the plant will proceed as follows :

$$
\mathrm{NO}_{3}^{-}+8 \mathrm{H} \longrightarrow \mathrm{NH}_{3}+2 \mathrm{H}_{2} \mathrm{O}+\mathrm{OH}^{-}
$$

4) In series a the slope of $\mathrm{N}$ in the second stage again indicates the rate of dilution as a result of growth. The $\mathrm{C}$ cations and the $\mathrm{A}$ anions also show a point of deflection, although the last part of these lines is not so steep as in the case of nitrogen. The uptake of $\mathbf{C}$ and $\mathbf{A}$ is actually retarded relatively to the growth, and continues at a lower intensity. Discontinuities in the trend also occur in series $b$, but these are too small to have a marked effect on the cation-anion ratio.

Since these relationships have still not been adequately explained they are not discussed further. 
so that it causes no change in the existing electroneutrality, the nitrate anion being replaced by a hydroxyl anion. The organic nitrogen formed in the metabolism has the reduction level of $\mathrm{NH}_{3}$ and is hereafter designated by $\mathrm{N}$.

The first uptake of nitrate will be accompanied by a cation equivalent $\left(\mathrm{C}^{+}\right)$. The subsequent reduction produces the anion hydroxyl, which eventually after the addition of carbon dioxide may be present in the form of a bicarbonate anion. The corresponding anion equivalent is recorded in the balance under nitrogen, so that the cation-anion ratio of this uptake is still equal to 1 after the reduction of nitrate.

If it were possible to exchange the hydroxyl or bicarbonate anion for a nitrate anion from the medium, after its reduction hydroxyl would again be available for a subsequent exchange, etc., so that the nitrate uptake could continue independently of further cation uptake. Hence in the scheme

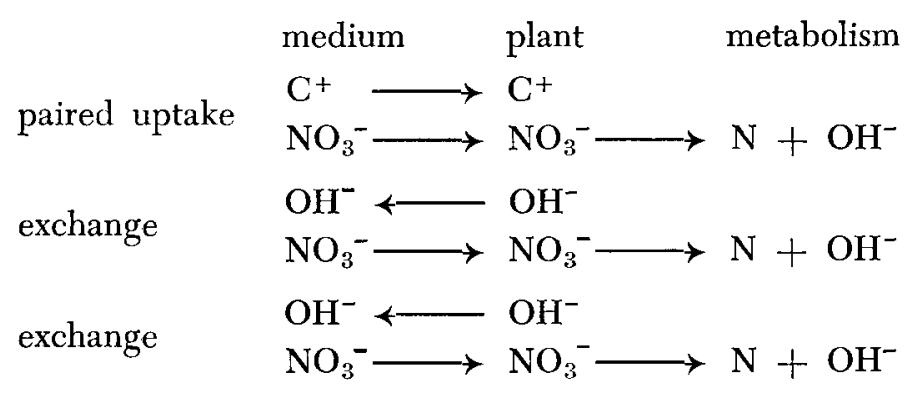

etc.

Whereas in this scheme the first uptake represents a cation-anion ratio of 1 , this ratio falls rapidly as a result of metabolism and anion exchange. The secretion of alkali in the medium is clearly observable in nitrate-containing nutrient solutions as an increase in the $\mathrm{pH}$ during the first weeks of regrowth of clipped plants.

There are several ways in which this exchange cycle can be terminated. In the first place it will occur when nitrate in the medium is exhausted. It will then only be possible for exchange to occur with another anion, and if this is not reduced by metabolism a further anion uptake will only be possible provided an equivalent cation $\left(\mathrm{C}^{+}\right)$is taken up at the same time.

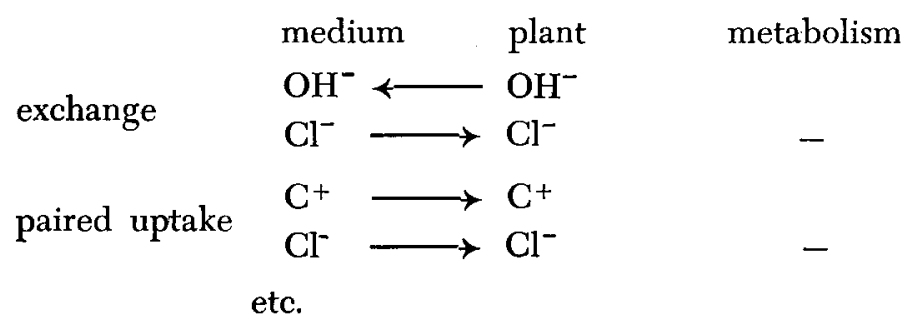

In the second place, the hydroxyl formed can be utilised in the formation of an organic anion which is no longer suitable for exchange. In this case it will be necessary for the uptake of succeeding nitrate anions to be accompanied by the uptake of an equivalent of cations, thereby leading to a paired nitrate-cation uptake. 


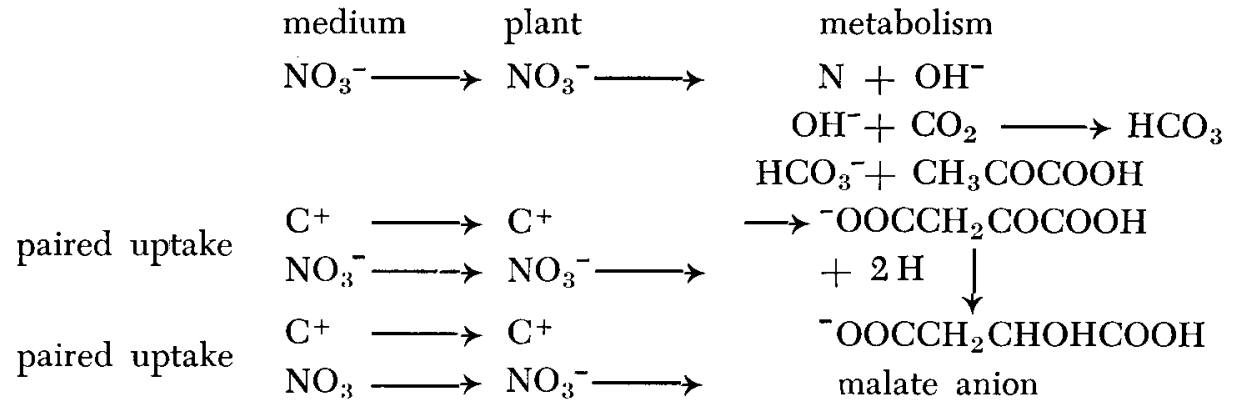

etc.

As an example the scheme shows the fixation of bicarbonate by pyruvic acid with the formation of oxaloacetic acid (Wood-Werkman reaction) and the subsequent reduction to malic acid. A reaction of bicarbonate with formic acid might lead in a similar manner to the formation of oxalic acid. This hypothesis may afford some help in explaining the greater production of organic acids in the nitrate nutrition of the plant as compared to other nitrogen sources (cf., for example, Scharrer and Jung, 1954).

The intensity at which the exchange cycle is able to proceed will be determined in the first place by the rate of nitrate assimilation and hence by the growth of the plant. Moreover it will not be possible to make full use of this cycle because exchange is always possible with an anion which is not reduced in the metabolism, e.g. chloride, as a result of which part of the capacity is lost. In conclusion, the result of a formation of organic acids is that not all the hydroxyl is used for the purpose of exchange, its equivalency being partly transferred to less mobile organic anions.

The exchange cycle might therefore provide an explanation of the low cation-anion ratio occurring during the period of active nitrogen uptake and assimilation. As soon as this cycle begins to operate less efficiently, the paired uptake will come relatively more to the fore as growth continues, resulting in an increase in the cation-anion ratio. After the available nitrogen has been exhausted, the simultaneous uptake begins to predominate to a relatively higher extent and the cation-anion ratio increases more rapidly.

According to the present hypothesis the paired uptake might also be promoted by the formation of organic acids. Their production would in this case not be a response to excess cation uptake (JACOBSON, 1955) but the metabolic cause of a relatively greater cation absorption by the growing plant.

A similar scheme may be drawn up for the uptake of nitrogen in the form of ammonium. After the assimilation of ammonium to organic nitrogen there remains a hydrogen ion which can be utilized for cation exchange. If the exchange always occurs with ammonium, its uptake can proceed independently of the anion uptake. This exchange cycle is terminated after depletion, when the further exchange takes place entirely with a cation not converted in the metabolism, e.g. potassium. Thereafter the paired uptake of cation and anion equivalents will begin to predominate.

If nitrogen is included as a cation in plants fed with ammonium, the result is a very high cation-anion ratio (ScharRer and JuNG, 1955). If nitrogen 
is also included in the anions in this case, the ratio is low, but it may be expected to increase in this instance also when the nitrogen uptake and assimilation decreases. The difference in the effect of ammonium and nitrate in nutrition on the cation-anion ratio may consequently not be as great as might have been expected if BEAR's rule were to apply strictly. If nitrogen is irrespective of nitrate or ammonium uptake and assimilation, always included in the anions, we may be confronted in both cases with an initially low ratio resulting from an excessive nitrogen uptake which increases when there is a decline in the nitrogen uptake and assimilation.

\section{References}

Alberda, Th.: Plant and Soil 8 (1957) 199.

BEAR, F. E. : Agronomy Journ. 42 (1950) 176.

Dijkshoorn, W.: Netherl. J. Agric. Sci. 5 (1957) 81.

- - Netherl. J. Agric. Sci. 5 (1957) 233.

- - : Netherl. J. Agric. Sci. 6 (1958) 131.

Frankena, H. J.: Versi. Landbouwk. Onderz. 40 (1934) 23.

Itallie, Th. B. van : Versl. Landbouwk. Onderz. 40 (1934) 639.

Jacosson, L. : Plant Physiology 30 (1955) 264.

Scharrer, K. and J. Jung : Ztschr. Pflanzenern., Dïngung, Bodenkunde 66 (1954) 1.

- -, - - : Ztschr. Pflanzenern., Dïngung, Bodenkunde 7 I (1955) 76. 